\title{
Impact of facial bone deformity on nasal shape
}

\author{
Victor Ravelo, ${ }^{1,2}$, Eder A. Sigua-Rodriguez ${ }^{3}$, Ziyad S. Haidar ${ }^{4,5}$, Leonardo Brito ${ }^{1,2}$, Marcelo Parra ${ }^{1,6}$, Sergio \\ Olate $^{1,6}$ \\ ${ }^{1}$ Center of Excellence in Morphological and Surgical Studies, University of La Frontera, Temuco 4780000, Chile. \\ ${ }^{2}$ Facultad de Ciencias de la Salud, Universidad Autónoma de Chile, Temuco 4780000, Chile. \\ ${ }^{3}$ Centro de Investigaciones del Colegio Odontológico (CICO), Institución Universitaria Colegios de Colombia, Bogotá 760008, \\ Colombia. \\ ${ }^{4}$ BioMAT'X, Facultad de Odontología, Universidad de los Andes, Santiago 7550000, Chile. \\ ${ }^{5}$ Centro de Investigación e Innovación Biomédica (CIIB), Facultad de Medicina, Universidad de los Andes, Santiago 7550000, \\ Chile. \\ ${ }^{6}$ Division of Oral, Facial and Maxillofacial Surgery, University of La Frontera, Temuco 4780000, Chile.
}

Correspondence to: Prof. Sergio Olate, Division of Oral, Facial and Maxillofacial Surgery, University of La Frontera, Claro Solar 115, Temuco 4780000, Chile. E-mail: sergio.olate@ufrontera.cl

How to cite this article: Ravelo V, Sigua-Rodriguez EA, Haidar ZS, Brito L, Parra M, Olate S. Impact of facial bone deformity on nasal shape. Plast Aesthet Res 2021;8:19. https://dx.doi.org/10.20517/2347-9264.2020.197

Received: 25 Oct 2020 First Decision: 15 Dec 2020 Revised: 1 Mar 2021 Accepted: 16 Mar 2021 Available online: 8 Apr 2021

Academic Editor: Raúl González-García Copy Editor: Xi-Jun Chen Production Editor: Xi-Jun Chen

\begin{abstract}
Aim: The aim of this study was to analyze nose shape and size in subjects with sagittal facial deformities.

Methods: One hundred fifteen subjects were included for orthognathic surgery; the previous cone bean computed tomography was used to perform the analysis. The sample consisted of 46 males (40\%) and 69 females (60\%); the nasal morphology in frontal view and profile, the deviation of the nasal septum, the skeletal class and the sagittal position of the maxilla were compared using the Spearman test, considering a $P$ value $<0.05$.
\end{abstract}

Results: Males had a greater vertical nasal skeletal measurement $(P=0.0006)$, greater cartilaginous nasal height ( $P=0.0001)$ and greater horizontal distance between the A point and $\operatorname{Prn}(P=0.001)$. Considering the sagittal position of the maxilla, subjects with maxillary prognathism had a higher nasal morphology value than subjects with a retrognathic maxilla. In addition, nasal septum deviation was statistically related to facial class $\|(P=0.03)$ with significantly more deviation than class III subjects.

Conclusion: It may be concluded that there are variables in facial deformities related to nose shape and have to be included in the surgical plan for orthognathic surgery or rhinoplasty. 
Keywords: Facial deformity, nasal shape, orthognathic surgery, rhinoplasty

\section{INTRODUCTION}

Facial proportions and symmetry are important in the perception of beauty and function ${ }^{[1]}$. Harmony of the face, mouth and nose plays an important role in this scenario. Facial deformities could affect techniques and protocols for functional and aesthetic treatments ${ }^{[2-4]}$.

Structural variations of the nasal bones, cartilage and septum are associated with morphological variations and changes in proportions of the hard and soft tissues around the nasolabial region; it is related to the shape and position of the nasal tip, nasal width, nasolabial angulation and anatomy of the upper lip ${ }^{[5,6]}$.

On other hand, some patients with facial deformity are associated with nasal deformities and could be treated by orthognathic surgery and rhinoplasty to improve function and aesthetics ${ }^{[7,8]}$, since both techniques are significantly related to facial symmetry, function, stability and aesthetics ${ }^{[9]}$.

The aim of this study was to analyze nasal morphology in subjects with different types of facial deformities and to assess some variables to use in diagnosis and surgical planning.

\section{METHODS}

A descriptive study was conducted in male and female Caucasian subjects from Chile (South America), included for orthognathic surgery prior to the use of orthodontics. We excluded subjects with previous facial surgery, history of facial trauma, facial syndromes or conditions with significant morphological alteration and subjects with facial asymmetries due to deviation of the chin of more than $5 \mathrm{~mm}$ from the midline of the face. The subjects signed an informed consent form. The study was conducted in accordance with the Declaration of Helsinki, while protecting the integrity of the participants.

A 3D image obtained by cone-beam computed tomography was used and analyzed in the NewTom 3D software, model VGi EVO (Verona, Italy), with visualization field of $24 \mathrm{~cm} \times 19 \mathrm{~cm}$ and exposure parameters: $110 \mathrm{kV}, 8 \mathrm{~mA}$ and $15 \mathrm{~s}$. The image was obtained by a radiology specialist; the patient was placed in a vertical position, keeping the lips at rest, without forcing a body position; the patient remained in a resting position for the image capture.

\section{Sagittal analysis of the maxilla}

Facial skeletal class: The Steiner analysis was used to determine the A-Na-B angulation (A point: a landmark in the deepest zone of the anterior concavity of the maxillary bone; nasion: a landmark at the intersection of the internasal and frontal sutures; B point: a landmark in the deepest point of the anterior concavity of the maxilla). Angulation greater than $2^{\circ}$ was categorized as skeletal class II and angulation less than $2^{\circ}$ as skeletal class III [Figure 1].

Maxillary position: The Frankfurt plane was used, formed by the points Po-Or (porion: upper point of the external auditory canal; orbitale: lowest point of the orbit) and a perpendicular line was drawn passing through the Na point. To determine the position of the maxilla, the McNamara analysis was used, which measures the distance from the A point to the perpendicular (normality parameter $1 \mathrm{~mm}$ ). 


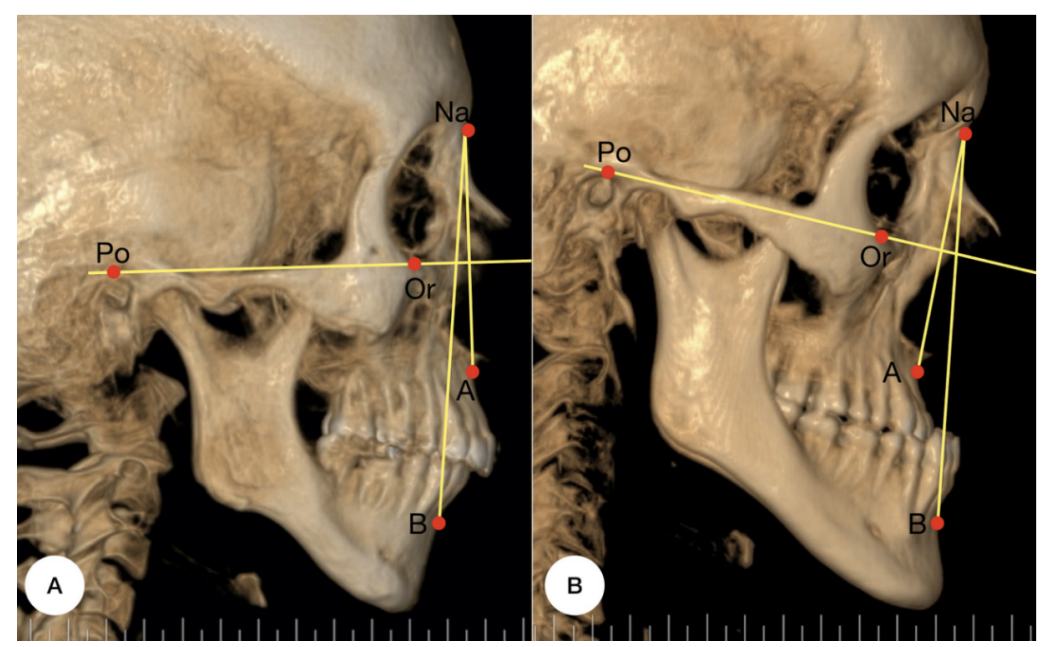

Figure 1. Cephalometric landmark used to determine the facial class and sagittal position of the maxilla and mandibula. The skeletal class (A-N-B) and anteroposterior position of the maxilla (Na-perpendicular-point $A$ ) and mandible (Na-perpendicular-Pog) were determined (A-B). A: Facial class II; B: Facial class III.

\section{Analysis of nasal morphology}

Frontal view

In the frontal analysis, the Ricketts analysis was used to determine nasal height and width. The length of the nasal cartilage vertically was obtained by the measurement performed by Olate et al. ${ }^{[10]}$ [Figure 2].

Nasal skeletal height: From the median point between the ZR-ZL points (transverse line that joins the right and left frontozygomatic sutures), a perpendicular line was drawn to the ANS (anterior nasal spine: most anterior point of the premaxilla on the median sagittal plane).

Nasal skeletal width: The distance between the right and left most lateral points of the pyriform cavity in the lower third of the nose $(\mathrm{CN}-\mathrm{CN})$.

Cartilaginous nasal height: The distance was determined from the lowest midpoint of the suture between the 2 nasal bones (NB) and the ANS.

To measure the deviation of the nasal septum, the measures proposed by Serifoglu et al. ${ }^{[11]}$ were used: a vertical line was drawn from the highest point of the crista galli; an angle line from the same point was in a tangential direction to the most deviated point of the septum (DT), obtaining a deviation angle. The classification described by Gencer et al..$^{[12]}$ was used, considering the deviation to be slight with an angulation $<9^{\circ}$, moderate with an angulation between $9^{\circ}$ and $15^{\circ}$ and severe greater than $15^{\circ}$.

\section{Lateral view}

Nasal length: The measurements proposed by Olate et al.$^{[10]}$ were used, which use the ANS, A point and the Prn point (pronasal: most anterior and prominent point of the tip of the nose) as a reference, relating nasal hard tissue and maxillary position in a linear measurement to the Prn.

Nasolabial angle: The Ricketts cephalometric analysis establishing the Cm-Sn-Ls angle (columella: most anterior point of the columella of the nose; subnasale: point of greatest concavity posterior to the columella of the nose; labrale superior: most prominent point of the edge of the upper lip) [Figure 3]. 


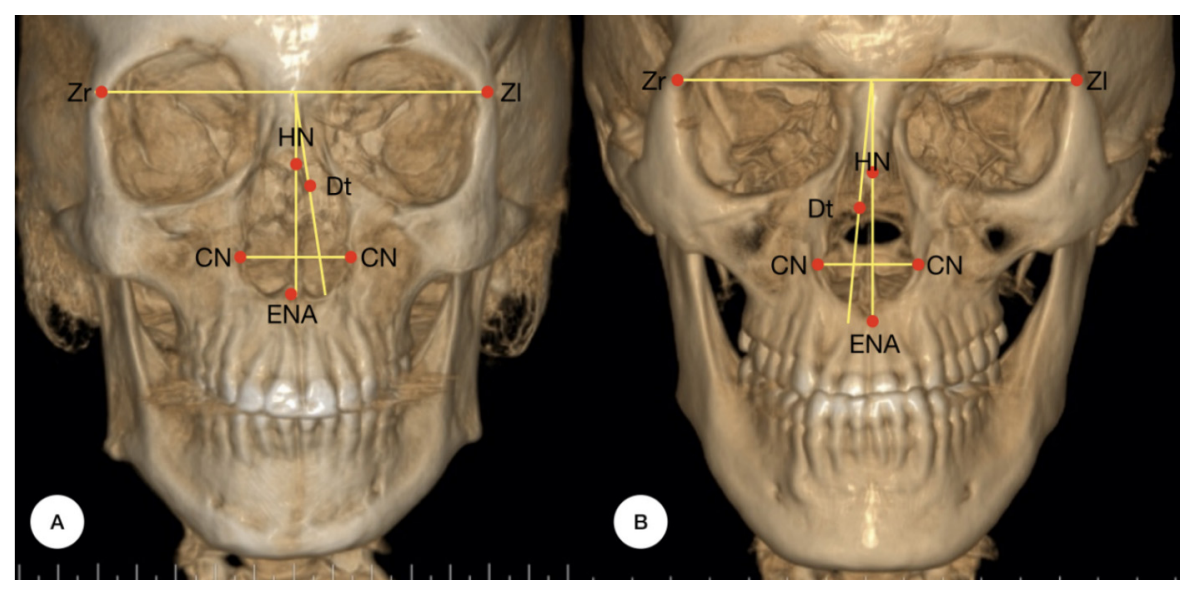

Figure 2. The nasal height (transverse line ZR-ZL-ANS), length of the nasal cartilage (NB-ANS), nasal width (CN-CN) and the deviation of the nasal septum (Cg-DT-ANS). A: Facial class II; B: Facial class III. ANS: anterior nasal spine.
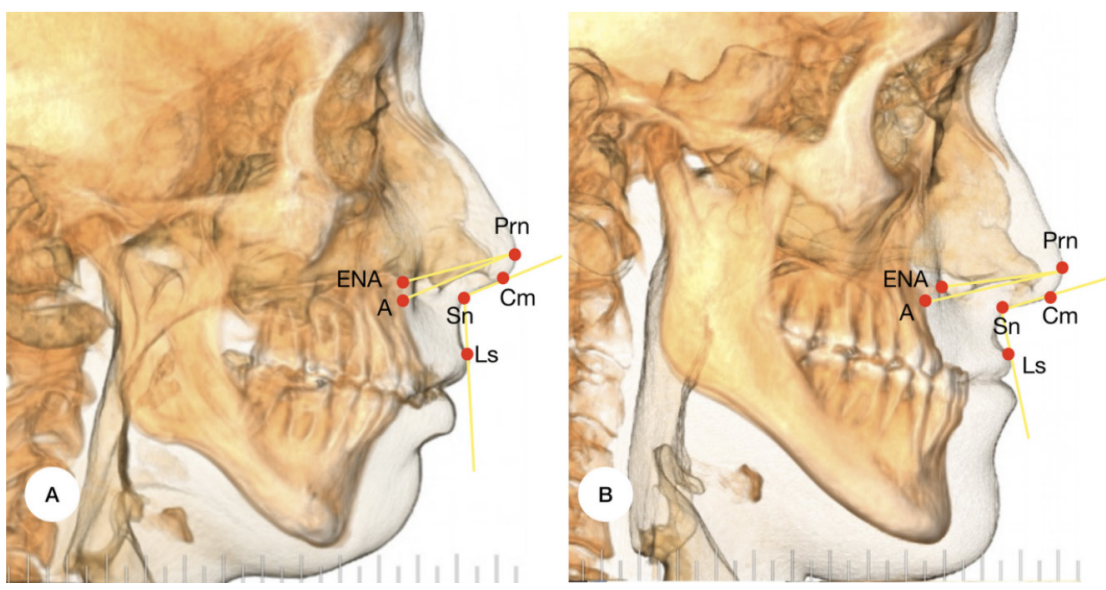

Figure 3. The nasal length was determined from 2 points (ANS-Prn/Point A-Prn) and nasolabial angle (Cm-Sn-Ls). A: Facial class II; B: Facial class III.

The measurements were taken by the same observer twice, with a 2-week interval between times. Using the kappa index, an agreement of 0.82 was observed. The results were tabulated and subjected to statistical analysis. A 95\% confidence interval was used. In addition, the Spearman test was performed to determine the correlation between the variables. A value of $P<0.05$ was considered to determine significant differences.

\section{RESULTS}

A total of 115 subjects were included, aged $27.8 \pm 11.6$ years (range 18 to 53 years). Included were 46 males $(40 \%)$ and 69 females (60\%). When comparing the nasal morphology between males and females [Table 1], differences were observed, where male subjects showed a greater skeletal vertical distance (ZR-ZL/ANS, $P=$ 0.0006), cartilaginous nasal height (NB-ANS, $P=0.0001)$ and horizontal distance between the A point and $\operatorname{Prn}(P=0.001)$.

Considering the sagittal position of the maxilla, subjects with maxillary prognathism showed a higher proportion in nasal morphology compared to subjects with retrognathic maxilla [Figure 4 and Figure 5]. 
Table 1. Distribution of the sample according to gender and the conditions of nose shape

\begin{tabular}{llllll}
\hline \multirow{2}{*}{ Nasal morphology } & \multicolumn{3}{c}{ Males } & \multicolumn{3}{c}{ Females } & \multirow{2}{*}{$\mathbf{0 . 0 5}$} \\
\cline { 2 - 6 } & Mean & SD & Mean & SD & $0.006^{\star}$ \\
\hline Nasal height & $46.50 \mathrm{~mm}$ & 3.19 & $44.94 \mathrm{~mm}$ & 2.96 & 0.40 \\
Nasal width & $19.89 \mathrm{~mm}$ & 2.50 & $19.85 \mathrm{~mm}$ & 2.28 & $0.0001^{\star}$ \\
Cartilage length & $32.34 \mathrm{~mm}$ & 4.42 & $29.86 \mathrm{~mm}$ & 3.15 & 0.13 \\
Septum deviation & $8.6^{\circ}$ & 2.79 & $8.4^{\circ}$ & 1.90 & $0.0001^{\star}$ \\
ANS - Prn & $25.82 \mathrm{~mm}$ & 2.39 & $24.34 \mathrm{~mm}$ & 1.61 & $0.0001^{\star}$ \\
Point A - Prn & $31.19 \mathrm{~mm}$ & 2.76 & $29.27 \mathrm{~mm}$ & 2.06 & 0.41 \\
Nasal angle & $102.36^{\circ}$ & 12.46 & $103.20^{\circ}$ & 8.5 & \\
\hline
\end{tabular}

*Indicates a statistically significant difference. ANS: Anterior nasal spine; Prn: pronasal; SD: standard deviation.
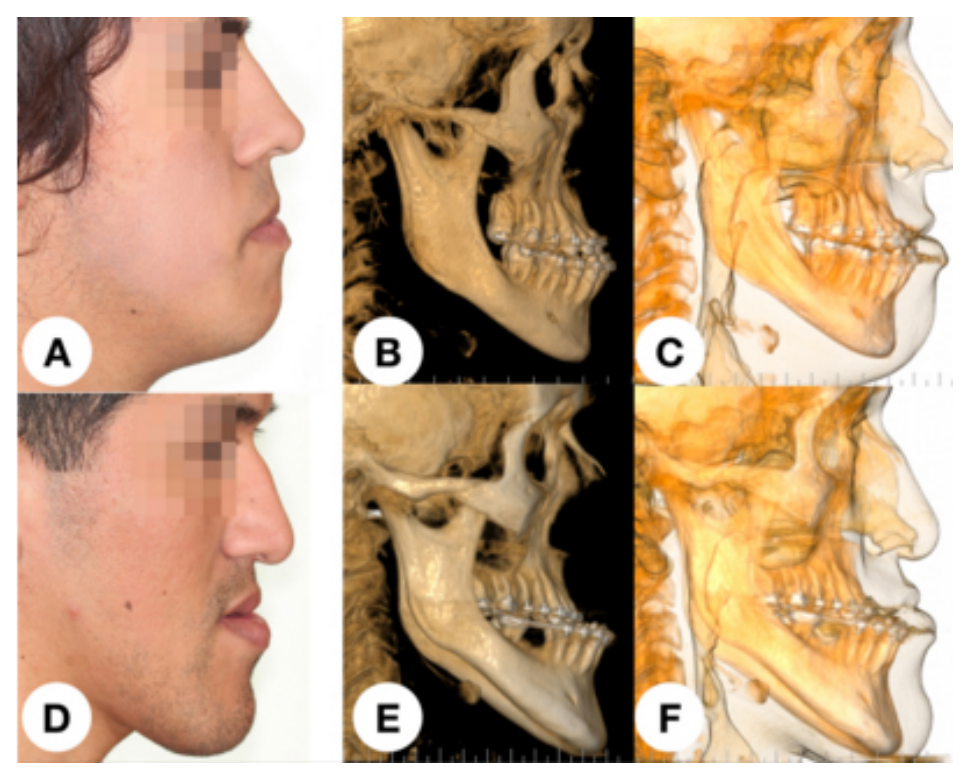

Figure 4. Sequence of subjects under class III facial deformity. A and D showing the classical skeletal patterns involved in sagittal deficiency of the middle third of the face. B and $\mathrm{E}$ show the morphology related to the maxillary bone and the concavity observed in the lateral area of the nose. $\mathrm{C}$ and $\mathrm{F}$ show the ratio bone-to-soft tissue; the concavity and the position of the maxillary bone and anterior nasal spine is related to lack in support for the lower area of the nose. The more posterior pyriform contouring will show a poor support for soft tissue and the cartilage of the nose.

The position of the maxilla was related to the distance between the ANS and Prn $(P=0.04)$ and the nasolabial angle $(P=0.01)$, being greater in subjects with maxillary prognathism and less in subjects with maxillary retrognathia [Table 2].

It was observed that class II subjects displayed significantly greater cartilaginous vertical height (NB-ANS, $P$ $=0.03)$, greater distance between the ANS point and $\operatorname{Prn}(P=0.03)$, greater distance between the A point and $\operatorname{Prn}(P=0.03)$ and a more open nasolabial angle $(P=0.02)$ [Table 3]. In addition, when comparing the variables of facial deformity and nasal septum deviation, differences could be established $(P=0.03)$, showing the class II subjects with significantly more deviation of the nasal septum than the class III subjects [Table 4].

\section{DISCUSSION}

Nasal morphology is linked to facial morphology and the results of this study showed significant relations 
Table 2. Distribution of the sample according to the sagittal position of the maxilla and the conditions of nose shape

\begin{tabular}{|c|c|c|c|c|c|c|c|}
\hline \multirow{2}{*}{ Nasal morphology } & \multicolumn{2}{|c|}{ Mx I } & \multicolumn{2}{|c|}{ Mx II } & \multicolumn{2}{|c|}{ Mx III } & \multirow{2}{*}{$P<0.05$} \\
\hline & Mean & SD & Mean & SD & Mean & SD & \\
\hline Nasal skeletal height & $46.06 \mathrm{~mm}$ & 2.78 & $45.20 \mathrm{~mm}$ & 3.15 & $46 \mathrm{~mm}$ & 3.6 & 0.39 \\
\hline Nasal skeletal width & $19.45 \mathrm{~mm}$ & 1.89 & $19.76 \mathrm{~mm}$ & 2.48 & $20.76 \mathrm{~mm}$ & 2.52 & 0.43 \\
\hline Cartilaginous nasal height & $29.96 \mathrm{~mm}$ & 3.09 & $30.20 \mathrm{~mm}$ & 3.49 & $31.28 \mathrm{~mm}$ & 3.88 & 0.41 \\
\hline Nasal septum deviation & $8.90^{\circ}$ & 2.32 & $8.47^{\circ}$ & 2.44 & $8.42^{\circ}$ & 2.35 & 0.14 \\
\hline ANS - Prn & $24.90 \mathrm{~mm}$ & 1.59 & $24.84 \mathrm{~mm}$ & 2.19 & $25.23 \mathrm{~mm}$ & 2.44 & 0.12 \\
\hline Point A - Prn & $30.12 \mathrm{~mm}$ & 2.06 & $29.74 \mathrm{~mm}$ & 2.66 & $30.08 \mathrm{~mm}$ & 2.73 & $0.04^{*}$ \\
\hline Nasolabial angle & $103.38^{\circ}$ & 8.10 & $103.36^{\circ}$ & 10.74 & $100.60^{\circ}$ & 11.59 & $0.01^{\star}$ \\
\hline
\end{tabular}

"Indicates a statistically significant difference. Mxl: Orthognathic maxilla; Mxll: retrognathic maxilla; MxIII: prognathic maxilla; ANS: anterior nasal spine; Prn: pronasal; SD: standard deviation.

Table 3. Distribution of the sample according to facial skeletal class and conditions of nose shape

\begin{tabular}{llllll}
\hline \multirow{2}{*}{ Nasal morphology } & \multicolumn{2}{c}{ Facial class II } & \multicolumn{2}{c}{ Facial class III } & \multirow{2}{*}{$\boldsymbol{P}<\mathbf{0 5}$} \\
\cline { 2 - 6 } & Mean & SD & Mean & SD & 0.35 \\
Nasal skeletal height & $45.50 \mathrm{~mm}$ & 3.14 & $45.70 \mathrm{~mm}$ & 3.17 & 0.09 \\
Nasal skeletal width & $18.52 \mathrm{~mm}$ & 2.28 & $20.07 \mathrm{~mm}$ & 2.48 & 0.18 \\
Cartilaginous nasal height & $35.54 \mathrm{~mm}$ & 3.44 & $31.29 \mathrm{~mm}$ & 3.52 & $0.03^{\star}$ \\
Nasal septum deviation & $8.8^{\circ}$ & 2.61 & $7.4^{\circ}$ & 1.18 & 0.12 \\
ANS - Prn & $25.14 \mathrm{~mm}$ & 2.17 & $23.61 \mathrm{~mm}$ & 1.19 & $0.03^{\star}$ \\
Point A - Prn & $30.32 \mathrm{~mm}$ & 2.50 & $28.58 \mathrm{~mm}$ & 2.52 & $0.02^{\star}$ \\
Nasolabial angle & $107.2^{\circ}$ & 9.38 & $100.6^{\circ}$ & 11.25 & ${ }^{\circ}$ \\
\hline
\end{tabular}

"Indicates a statistically significant difference. ANS: Anterior nasal spine; Prn: pronasal; SD: standard deviation.

Table 4. Distribution frequency of the facial class with nasal septum deviation

\begin{tabular}{|c|c|c|c|c|c|c|c|}
\hline & \multicolumn{2}{|c|}{ Slight nasal septum deviation } & \multicolumn{2}{|c|}{ Moderate nasal septum deviation } & \multicolumn{2}{|c|}{ Severe nasal septum deviation } & \multirow{2}{*}{$P<0.05$} \\
\hline & $\mathbf{N}$ & $\%$ & $\mathbf{N}$ & $\%$ & $\mathbf{N}$ & $\%$ & \\
\hline Facial class II & 33 & 28.69 & 35 & 30.43 & 3 & 2.60 & $0.03^{\star}$ \\
\hline Facial class III & 26 & 22.60 & 18 & 15.65 & 0 & 0 & \\
\hline
\end{tabular}

"Indicates a statistically significant difference. N: Subjects included for each characteristic in the cephalogram.

between some variables. The mode of breathing and nasal anatomy have been related to facial characteristics and the development and shape of the face ${ }^{[13,14]}$. For that reason, the surgical correction of maxilla, mandible and nose could increase postoperative patient satisfaction ${ }^{[15-17]}$.

Our results showed some relations between the aspects of nasal and facial morphology. Maxillary position reported significant relations with the morphology of the nose, being linked to the sagittal increase in the nose as well as in the nasolabial angle in subjects with facial class II; likewise, these variables were significantly smaller in subjects with facial class III. It is possible that in the case of maxillary retrognathia, there would be a smaller nose and a descending nasal tip, whereas the prognathic maxilla would show greater sagittal dimensions at the base of the nose together with an increase in the rotation of the nasal tip associated with an increase in the nasolabial angle. Figure 4 and Figure 5 show a good approach to the morphology of the maxillary bone and the conditions observed in the nasal support. In the nasal anatomy and development, multiple variables are included to obtain the final morphology; however, the maxillary support and the pyriform morphology could be important variables in the final anatomy and position of the 


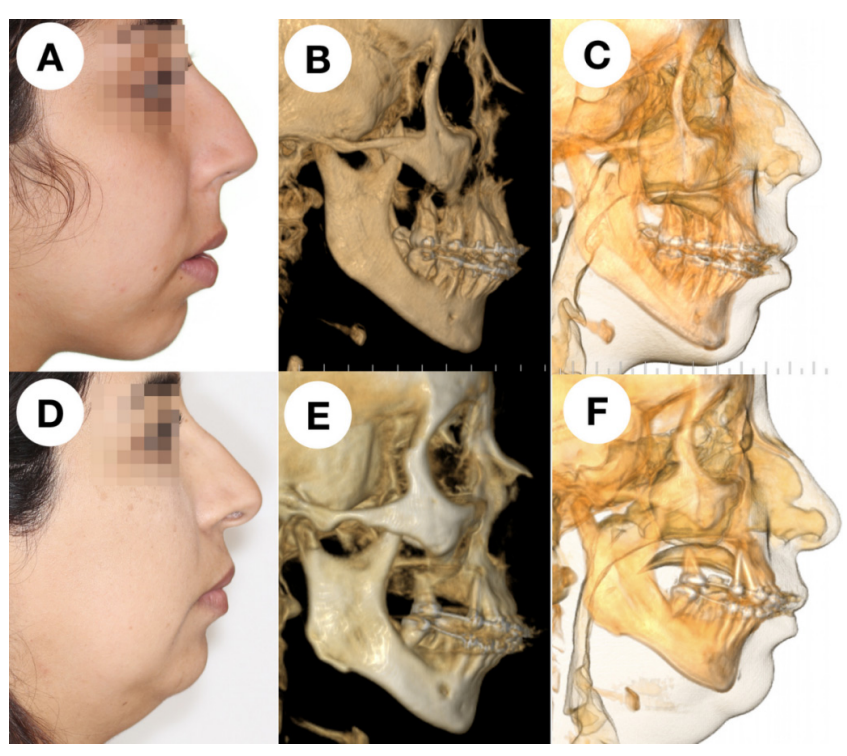

Figure 5. Sequence of subjects with class II facial deformity. A and D show the classical facial pattern in class II patient, with a deficiency in sagittal projection of the maxilla. B and E show the position of the facial skeleton in a better support for the soft tissue; concavity in the middle third is not observed, usually with a good projection of the maxillary bone and nasal spine. $\mathrm{C}$ and $\mathrm{F}$ show the position of the maxillary bone and the support for soft tissue and cartilage of the nose, better than in class III faces.

nose.

In the general population, almost $80 \%$ show septum deviation ${ }^{[18,19]}$; in our sample, $61.72 \%$ of subjects with a class II facial deformity displayed septum deviation, being significantly greater than in subjects with a facial class III (38.25\%). The average septum deviation in the general population is $13.5^{\circ}\left( \pm 5^{\circ}\right)^{[20]}$, being located in a slight to moderate area; in our sample, conditions were similar, where we found more aggressive deviations in subjects with a class II facial deformity.

In terms of vertical and sagittal size of the nose, facial class II subjects showed a significantly larger size than the subjects with facial class III. These data are interesting since limited studies have shown nasal morphology related to facial deformities ${ }^{[21-23]}$. Posnick and Agnihotri ${ }^{[24]}$ indicated that in subjects with facial deformity, there is a high likelihood of observing functional nasal alterations due to a septum deviation, turbinate hypertrophy or opening of the nasal cavity, showing the role of nasal anatomy and function in a facial deformity condition.

In the case of orthognathic surgery, nasal change will be observed with increase in width of the base and raising of the tip ${ }^{[25-27]}$. Waite and Matukas ${ }^{[28]}$ reported that rhinoplasty together with orthognathic surgery had to be performed in cases of aesthetic or functional deviation of the nasal septum, minor defects of the tip or morphology of the alar base and in cases of serious deformities of the nasal bridge ${ }^{[29]}$. They showed $63 \%$ nasal deformity in facial class II and $60 \%$ nasal deformity in facial class III submitted to combined procedure. Accordingly, $94 \%$ of patients submitted to orthognathic surgery and rhinoplasty accepted the last procedure because it could be done in one surgical time ${ }^{[8]}$.

This article shows the importance of performing a complementary morphological analysis of the face. On the other hand, the size and composition of the sample, ethnic origin and age are important factors in facial surgery, and new research is still necessary in this field. However, this article shows some data of value for 
new approaches. It may be concluded that there are some variables in class II and class III facial deformities linked to nasal morphology. Nasal morphology has to be included in the orthognathic and orthofacial surgery plan to improve the function and aesthetics of the face.

\section{DECLARATIONS}

\section{Authors' contributions}

Conception, data acquisition, writing, final approve: Ravelo $\mathrm{V}$

Data acquisition, technical support, final approve: Sigua-Rodriguez EA

Data acquisition, literature review, technical support, revision and final approve: Haidar ZS

Technical support, writing, literature review, revision and final approve: Brito L

Technical support, literature review, revision and final approve: Parra $\mathrm{M}$

Conception, design, literature review, editing, writing and final approve: Olate $\mathrm{S}$

\section{Availability of data and materials}

Not applicable.

\section{Financial support and sponsorship}

None.

\section{Conflicts of interest}

All authors declared that there are no conflicts of interest.

\section{Ethical approval and consent to participate}

The study was conducted in accordance with the Declaration of Helsinki, ethical approval 069/16.

\section{Consent for publication}

The presented individual details and images were obtained with the patient's consent for publication.

\section{Copyright}

(c) The Author(s) 2021.

\section{REFERENCES}

1. Carvalho B, Ballin AC, Becker RV, Berger CA, Hurtado JG, Mocellin M. Rhinoplasty and facial asymmetry: analysis of subjective and anthropometric factors in the Caucasian nose. Int Arch Otorhinolaryngol 2012;16:445-51. DOI PubMed PMC

2. Krane NA, Markey JD, Moneta LB, Kim MM. Aesthetics of the nasal dorsum: proportions, light, and shadow. Facial Plast Surg 2017;33:120-4. DOI PubMed

3. Rohrich RJ, Villanueva NL, Small KH, Pezeshk RA. Implications of facial asymmetry in rhinoplasty. Plast Reconstr Surg 2017;140:510-6. DOI PubMed

4. Yi JS, Jang YJ. Frequency and characteristics of facial asymmetry in patients with deviated noses. JAMA Facial Plast Surg 2015;17:265-9. DOI PubMed

5. de Sousa Gil A, Guijarro-Martínez R, Haas OL Jr, Hernández-Alfaro F. Three-dimensional analysis of nasolabial soft tissue changes after Le Fort I osteotomy: a systematic review of the literature. Int J Oral Maxillofac Surg 2019;48:1185-200. DOI PubMed

6. Sykes JM, Kim JE, Shaye D, Boccieri A. The importance of the nasal septum in the deviated nose. Facial Plast Surg 2011;27:413-21. DOI PubMed

7. Chatrath P, De Cordova J, Nouraei SA, Ahmed J, Saleh HA. Objective assessment of facial asymmetry in rhinoplasty patients. Arch Facial Plast Surg 2007;9:184-7. DOI PubMed

8. Raffaini M, Cocconi R, Spinelli G, Agostini T. Simultaneous rhinoseptoplasty and orthognathic surgery: outcome analysis of 250 consecutive patients using a modified Le Fort I osteotomy. Aesthetic Plast Surg 2018;42:1090-100. DOI PubMed

9. Nouraei SA, Pulido MA, Saleh HA. Impact of rhinoplasty on objective measurement and psychophysical appreciation of facial symmetry. Arch Facial Plast Surg 2009;11:198-202. DOI PubMed

10. Olate S, Cantín M, Vásquez B, Olate G. Estructura nasal en pacientes con deformidad facial clase III. Int J Morphol 2014;32:334-8. DOI

11. Serifoglu I, Oz İ̇, Damar M, Buyukuysal MC, Tosun A, Tokgöz Ö. Relationship between the degree and direction of nasal septum deviation and nasal bone morphology. Head Face Med 2017;13:3. DOI PubMed PMC 
12. Gencer ZK, Ozkırış M, Okur A, Karaçavuş S, Saydam L. The effect of nasal septal deviation on maxillary sinus volumes and development of maxillary sinusitis. Eur Arch Otorhinolaryngol 2013;270:3069-73. DOI PubMed

13. Bakor SF, Enlow DH, Pontes P, De Biase NG. Craniofacial growth variations in nasal-breathing, oral-breathing, and tracheotomized children. Am J Orthod Dentofacial Orthop 2011;140:486-92. DOI PubMed

14. Lee JS, Lee H, Kim JW, Chang M, Park M, Baek S. Association of facial asymmetry and nasal septal deviation in acquired nasolacrimal duct obstruction in East Asians. J Craniofac Surg 2013;24:1544-8. DOI PubMed

15. Posnick JC, Wallace J. Complex orthognathic surgery: assessment of patient satisfaction. J Oral Maxillofac Surg 2008;66:934-42. DOI PubMed

16. Yim S, Baek SH. Difference in degrees of satisfaction with orthognathic surgery and orthodontic treatment between skeletal class III and cleft patients. J Craniofac Surg 2019;30:985-91. DOI PubMed

17. Denadai R, Chou PY, Seo HJ, et al. Patient- and 3D morphometry-based nose outcomes after skeletofacial reconstruction. Sci Rep 2020;10:4246. DOI PubMed PMC

18. Prasad S, Varshney S, Bist SS, Mishra S, Kabdwal N. Correlation study between nasal septal deviation and rhinosinusitis. Indian J Otolaryngol Head Neck Surg 2013;65:363-6. DOI PubMed PMC

19. Roblin DG, Eccles R. What, if any, is the value of septal surgery? Clin Otolaryngol Allied Sci 2002;27:77-80. DOI PubMed

20. Orhan I, Aydın S, Ormeci T, Yılmaz F. A radiological analysis of inferior turbinate in patients with deviated nasal septum by using computed tomography. Am J Rhinol Allergy 2014;28:e68-72. DOI PubMed

21. Hafezi F, Naghibzadeh B, Nouhi A, Yavari P. Asymmetric facial growth and deviated nose: a new concept. Ann Plast Surg 2010;64:47-51. DOI PubMed

22. Haraguchi S, Takada K, Yasuda Y. Facial asymmetry in subjects with skeletal class III deformity. Angle Orthod 2002;72:28-35. DOI PubMed

23. Rodrigues MM, Passeri LA, Monnazzi MS, Gabrielli MFR, Gabrielli MAC, Pereira-Filho VA. Evaluation of nasal obstruction in various sagittal skeletal deformity of jaws. J Craniofac Surg 2017;28:e790-2. DOI PubMed

24. Posnick JC, Agnihotri N. Consequences and management of nasal airway obstruction in the dentofacial deformity patient. Curr Opin Otolaryngol Head Neck Surg 2010;18:323-31. DOI PubMed

25. Dantas WR, Silveira MM, Vasconcelos BC, Porto GG. Evaluation of the nasal shape after orthognathic surgery. Braz J Otorhinolaryngol 2015;81:19-23. DOI PubMed

26. Olate S, Zaror C, Blythe JN, Mommaerts MY. A systematic review of soft-to-hard tissue ratios in orthognathic surgery. Part III: Double jaw surgery procedures. J Craniomaxillofac Surg 2016;44:1599-606. DOI PubMed

27. Olate S, Zaror C, Mommaerts MY. A systematic review of soft-to-hard tissue ratios in orthognathic surgery. Part IV: 3D analysis - Is there evidence? J Craniomaxillofac Surg 2017;45:1278-86. DOI PubMed

28. Waite PD, Matukas VJ. Indications for simultaneous orthognathic and septorhinoplastic surgery. J Oral Maxillofac Surg 1991;49:13340. DOI PubMed

29. Seah TE, Bellis H, Ilankovan V. Orthognathic patients with nasal deformities: case for simultaneous orthognathic surgery and rhinoplasty. Br J Oral Maxillofac Surg 2012;50:55-9. DOI PubMed 